\title{
Las emociones: una breve historia en su marco filosófico y cultural en la Antigüedad
}

\author{
Iván Alfonso Pinedo Cantillo*,** \\ Jaime Yáñez Canal***
}

\section{Resumen}

Aunque las emociones se encuentran en el núcleo de quienes somos, su naturaleza y estructura continúa siendo hoy en día un amplio campo de investigación para diferentes disciplinas científicas. No obstante, como muchos otros temas de investigación actual, las emociones tienen unos antecedentes, una historia que conviene tener presente para ubicar los conceptos, los debates y las diversas aproximaciones teóricas en el marco cultural y las tradiciones de pensamiento que les dieron origen. En este artículo, realizaremos un breve recorrido por la historia

* Citar como: Pinedo Cantillo, I. A. y Yáñez Canal, J. (2018). Las emociones: una breve historia en su marco filosófico y cultural en la época antigua. Cuadernos de Filosofía Latinoamericana, 39(119), 13-45. DOI: http://www.doi.org/10.15332/25005375.5049

* Filósofo, Teólogo, Magíster en Filosofía, Magíster en Administración Educativa, candidato a Doctor en Filosofia de la Universidad Nacional de Colombia. Miembro del grupo de investigación "Estudios sobre el desarrollo socio-moral", Departamento de Psicología, Universidad Nacional de Colombia. Bogotá, Colombia. Correo: iapinedoc@unal.edu.co

*** Psicólogo, doctor en Filosofía de la Katholische Universitaett Eichstaett, posdoctorado en la Universidad de Hannover. Profesor Asociado del Departamento de Psicologia, Facultad de Ciencias Humanas: Universidad Nacional de Colombia. Director del grupo de investigación "Estudios sobre el desarrollo socio-moral". Bogotá, Colombia. Correo: jyanezc@unal.edu.co 
de las emociones en la época antigua de tal manera que el lector pueda reconocer, a grandes rasgos, las interpretaciones y posturas originales que desencadenaron diversas comprensiones teóricas en torno a estos fenómenos físicos y mentales que conforman nuestra existencia.

Palabras clave: emoción, pasión, filosofía, historia, Antigüedad.

\section{The emotions: a brief history in its philosophical and cultural framework. Antiquity}

\section{Abstract}

Although emotions are at the core of who we are, their nature and structure continues to be a broad field of research for different scientific disciplines. However, like many other current research topics, emotions have a background, a history that should be kept in mind to locate concepts, debates and various theoretical approaches in the cultural framework and the traditions of thought that gave rise to them. In this article we will, therefore, carry out a brief tour of the history of emotions in the Antiquity in such a way that the reader can recognize, in broad strokes, the original interpretations and postures that triggered diverse theoretical approaches around these physical and mental phenomena that shape our existence.

Keywords: emotion, passion, philosophy, history, Antiquity.

\section{Introducción}

El término "emoción" ha demostrado ser desde la Antigüedad un concepto difícil de definir y una noción que congrega muy variadas interpretaciones. Desde los primeros filósofos griegos, la emoción ha estado en el centro de las preocupaciones reflexivas y de los intentos conceptuales que se ocupan de esclarecer y solucionar los difíciles problemas relacionados con el comportamiento y la acción humana. Desde la Antigüedad, las pasiones o emociones se consideraron como lazos que unen al hombre con lo que está fuera de él: con las cosas, con el mundo, con los demás seres humanos e, incluso, 
con la misma divinidad, de manera tal que es un campo de estudio que ocupa un lugar elevado y preponderante en la escala de las más nobles disciplinas que intentan comprender los problemas de mayor trascendencia en el hombre.

Como muchos otros temas de investigación actual, el problema de la naturaleza de las emociones y sus rasgos definitorios no es completamente nuevo. A lo largo de la historia de la filosofía, podemos constatar recurrentes enfoques teóricos que buscan explicar de una u otra manera la esencia de estos fenómenos de la existencia humana, de tal forma que las primeras aproximaciones al concepto de emoción han determinado el rumbo que han tomado las diversas posturas y discusiones a lo largo de los siglos. Siendo esto así, los debates conceptuales actuales en torno a las emociones demandan algunas referencias históricas que permiten comprender la génesis y el desarrollo de diversas posturas teóricas que se resisten a desaparecer, a la vez que posibilitan contextualizar algunas argumentaciones que se reeditan en distintas épocas del pensamiento humano. En este artículo, preocupados por aquellos supuestos que parecen estar cimentados en nuestro sentido común, intentaremos hacer un breve recorrido por la historia de las emociones en la Antigüedad de tal forma que el lector pueda reconocer, a grandes rasgos, la manera cómo se construyeron ciertas nociones que en el mundo contemporáneo subyacen en las investigaciones de muy variadas disciplinas.

Debido a que la literatura en torno las emociones es bastante extensa y enormemente variada, para realizar una historia de las conceptualizaciones sobre el término "emoción", resulta necesario asumir un determinado orden en la exposición. En nuestro objetivo, será la filosofía antigua la que nos permitirá comprender el desenvolvimiento de la pregunta acerca de la definición y naturaleza de las emociones. En este punto, reconoceremos cómo durante buena parte de la historia humana el concepto de emoción estuvo ligado a reflexiones propias de la filosofía moral, aspecto que nos permite contextualizar el origen de diversas discusiones y conceptos que hacen parte del acervo teórico en torno a estos fenómenos fundamentales de nuestra vida.

Ahora bien, por su carácter de "breve historia de las emociones", debemos ser claros en el alcance y en los límites de este artículo: se trata de una introducción para todo aquel lector que quiera comprender de manera sucinta el origen y desarrollo de las diversas perspectivas de análisis y teorías en torno a las emociones, de tal manera que cuente con un insumo fundamental para una ulterior investigación especializada al respecto. Cuando se sintetiza un tema tan amplio como la historia de las emociones, 
siempre se corre el riesgo de simplificar demasiado las ideas y dejar por fuera datos o autores que desde otras aproximaciones resultan importantes (por ejemplo, o desde la perspectiva de la educación y el cultivo de las emociones, o desde las emociones y el cuerpo, o desde la reflexión sobre las emociones y el poder); no obstante, confiamos en que el trabajo sea un aporte al estado actual en cuanto reconstruye aspectos pertinentes que conforman la noción de emoción.

Con estas precisiones, podemos iniciar nuestro recorrido a través de la filosofía antigua en la que empezó buena parte de la reflexión y discusión acerca de las emociones.

\title{
La comprensión filosófica de las emociones en la Antigüedad
}

\begin{abstract}
Alegría, amor, miedo, tristeza y odio son emociones que han acompañado la existencia humana desde tiempos inmemoriales, pero fue en la filosofía griega y romana antigua en la que aparecieron las primeras reflexiones que intentaban describir de una manera más detallada las características de estos fenómenos del alma. Todavía hoy resultan sorprendentes las diferentes posturas teóricas que algunos filósofos antiguos desarrollaron en torno a las emociones, de tal forma que muchos de sus planteamientos siguen teniendo enorme actualidad.
\end{abstract}

En el Mundo Antiguo, las pasiones humanas, del griego pathos, un cúmulo de estados corporales que se padecen sin intervención de la voluntad, constituyen uno de los temas predilectos de las tragedias griegas. ${ }^{1}$ En estas obras dramáticas, hombres y mujeres se ven sometidos de manera incontenible a fuerzas interiores de amor, odio,

1 En este apartado, no nos detenemos a hacer una completa diferenciación de los términos "pasión", "afecto", "sentimiento" y otros similares que fueron característicos en la historia de la filosofia hasta el siglo xIx antes de emplearse el término "emoción" como lo conocemos hoy en día. Pathos es un término filosófico rico de sentido en el Mundo Antiguo. La idea de dolor, sufrimiento, movimiento, conmoción, está presente en el término pathos entendido como estado pasivo, algo que el sujeto padece o sufre tanto desde un punto de vista físico como moral. En el teatro griego, pathos se asocia con lo patético, es decir, la excitación de pasiones tales como la tristeza, la indignación, el temor y la compasión como consecuencia de ver la condición humana sometida a los avatares de la fortuna. La reconstrucción histórica del paso o la transformación de la categoria antigua de "pasión" al concepto contemporáneo de emoción se encuentra ampliamente desarrollada en Dixon (2006). A pesar de que el término "emoción" es de uso bien reciente en la historia de la filosofía, lo usaremos de manera poco delimitada, dejando en claro que este concepto solo apareció de manera explícita en el siglo xIX. 
tristeza y miedo que los arrastran a cometer actos inconcebibles para una recta razón. Son personajes representativos de lo que viven miles de seres humanos a lo largo de su vida, en la que por circunstancias de la fortuna y las contingencias que acompañan a ciertos acontecimientos existenciales terminan sumergidos en cursos de acción inesperados, conflictivos y, la mayoría de las veces, penosos como consecuencia de pasiones que no pueden dominar. Ejemplos de estas pasiones son el odio hacia un enemigo, el amor desmedido por alguien, la tristeza profunda por la muerte de un ser querido o la vergüenza o culpa experimentada por actos que resultan repulsivos a nuestra propia consciencia. Son situaciones que muestran incluso a personas buenas realizando acciones malvadas que, en otras circunstancias, repudiarían desde sus compromisos morales, pero que, movidas por la fuerza de las pasiones, terminan ocasionando daños irreparables (Nussbaum, 1995).

En esta primera aproximación a las emociones, podemos vislumbrar un problema que atravesará toda la historia de la filosofía, como la discusión sobre la relación entre las emociones y la razón. Como anotamos en la anterior referencia a la tragedia, los seres humanos con frecuencia nos vemos abocados a situaciones en las que las emociones parecen tener un dominio sobre nuestra mente y comportamiento, de tal manera que podemos experimentarlas como reacciones que están por fuera de nuestro control. Esta realidad llevó a muchos pensadores antiguos a considerar las emociones como movimientos irracionales del alma o ajenos a la obediencia de la razón.

No obstante, a pesar de encontrar alusiones que condenan la pasión en la tragedia griega, hallamos en el mundo griego diversas doctrinas acerca de las emociones. En la filosofía clásica griega y romana, existen tanto posturas que condenan las emociones por librar una batalla con la razón en la lucha por el control de la psique humana como aquellas que rescatan su participación en la determinación de la conducta moral y las proponen como fuente de armonía y de dimensiones creativas en el actuar humano (Knuuttila, 2004). Platón, por ejemplo, es recordado en el Fedro por concebir las pasiones como caballos descarriados que debían ser controlados por el auriga que personificaba el intelecto o pensamiento. Si el auriga controla la pareja de caballos, le será posible elevarse y gozar de la contemplación de las ideas. Pero si, por el contrario, los caballos se le rebelan y no sabe controlarlos, su ineptitud le dificultará el acceso al mundo inteligible (Aristóteles, trad. en $1988,246 a)$. 
La relación entre razón y emoción aparece entonces desde la Antigüedad como una cuestión central tanto para el estudio de la naturaleza del actuar humano como para la comprensión de la justificación moral, los juicios y los valores. Desde esta época, se establecieron las dicotomías entre razón y emoción, y las diferentes versiones en cómo esta relación podría presentarse. Desde las posiciones extremas que condenan la emoción por ser un obstáculo a la razón, y como consecuencia se consideran experiencias negativas y disruptoras que malogran las conductas o las actitudes de los individuos, como aquellas que la consideran como un impulso o una fuerza que puede ser adecuadamente orientada hacia nobles propósitos y que sugiere una armonía entre diferentes niveles de la naturaleza humana.

En el Mundo Antiguo también constatamos un aspecto central en el estudio de las emociones, y es su relación con la vida moral. Para los griegos, las emociones están en estrecha relación con los problemas de la felicidad, la vida buena, la virtud y el dolor que atraviesa la existencia humana. Los éxitos y triunfos, los fracasos y desengaños, las dificultades de la vida en comunidad, la amistad y la educación de los ciudadanos son aspectos que en el Mundo Antiguo están en estrecha relación y proporción con las fuerzas pasionales: con la moderación y disciplina que les debe imponer la voluntad, o por el contrario, con las tempestades interiores que levantan si se les deja libres y desenfrenadas (Plamper, 2015).

En consecuencia, la posición que se adoptaba frente a las pasiones del hombre influía poderosamente en el estilo de vida individual y comunitario, en la forma de ver las relaciones humanas y en los criterios que se consideraban relevantes para alcanzar una vida feliz o lograda. Así se explica que desde tiempos antiguos se hayan elaborado sistemas filosófico-morales que se preocuparon directamente de las pasiones, porque consideraron que para el hombre era quizá el problema de mayor importancia.

Teniendo en cuenta las consideraciones anteriores, a grandes rasgos los planteamientos de los filósofos en torno a las emociones se pueden configurar en tres grandes orientaciones: las doctrinas que dotan de significado a las emociones, los que niegan este significado por ser fenómenos contrarios a la razón y las posturas que buscan integrar estas dos concepciones antagónicas. La oposición entre razón y emoción, y los intentos de conciliación entre estos dos conceptos, hacen parte de la historia de las emociones, de manera tal que en este artículo tendremos presente este horizonte 
de discusión como un problema relevante que congrega a autores provenientes de la filosofía, de la psicología y, más recientemente, de las neurociencias.

La tragedia, como ya se ha establecido, es una puesta en escena de cómo operan y se materializan en diferentes circunstancias las pasiones del alma, pero ¿dónde se originan, cuál es la naturaleza de estas reacciones que producen enormes males y también actos heroicos o llenos de compasión hacia los demás seres humanos? La respuesta proviene de la filosofía, originalmente de las reflexiones de Aristóteles. Nos adentramos, pues, en nuestra historia de las emociones.

\section{La visión aristotélica de las emociones}

Aristóteles no formuló una teoría completa y sistemática de las emociones, pero dejó diversos planteamientos al respecto en la Ética nicomaquea, la Ética eudemia, la Retórica y Acerca del alma. En sus escritos, Aristóteles sostiene que las pasiones en general van acompañadas de placer o dolor, las cuales conducen a cierta alteración o turbación corporal. El filósofo define la emoción como "aquellos sentimientos que hacen que la condición de un individuo se transforme a tal grado que su juicio quede afectado, y que van acompañados de placer o dolor" (Aristóteles, trad. en 1994, 1378a20). El análisis que hace Aristóteles de la experiencia emocional suele estar ligado al conocimiento moral, por tal motivo en algunas de sus obras realiza diferentes descripciones detalladas de las pasiones más comunes que afectan a los seres humanos en su relación con los demás y que, en general, deben ser manejadas adecuadamente para alcanzar la perfección de la naturaleza humana.

La tradición de la ética occidental, en la acepción general de la búsqueda de una comprensión racional de los principios de la conducta humana, comenzó con los griegos de la Antigüedad. La ética griega de todos los periodos gira, sustancialmente, en torno a dos términos, eudaimonía y areté, o bien según su traducción tradicional, felicidad y virtud (Aristóteles, trad. en 1985). Pensadores del Mundo Antiguo como Aristóteles, y también las escuelas de filosofía helenista como los estoicos y epicúreos, tendrán mucha influencia en la reflexión en torno a estos términos y las conductas que se desprenden de las consideraciones filosóficas relativas a estas realidades humanas. En este contexto de la historia de las emociones, conviene tener en cuenta este marco de reflexión, puesto que la visión de las pasiones en el Mundo Antiguo estará indisolublemente asociada a la pregunta por lo realmente deseable en la vida humana y a la 
cuestión central sobre el tipo de vida que uno debía vivir para alcanzar la eudaimonía o felicidad, y los criterios que conducen a una vida consumada (Rowe, 2007).

Las pasiones o emociones pueden contribuir, por tanto, al desarrollo de una serie de disposiciones que conducen a obrar correctamente y, de esta manera, a alcanzar una vida buena o lograda, o pueden convertirse en un obstáculo para que el ser humano alcance la eudaimonía, por eso no son ajenas a la reflexión ética. Las pasiones modelan nuestro actuar y configuran quiénes somos en realidad, es decir, están vinculadas a nuestro carácter: personas con virtudes de justicia, coraje, prudencia y sabiduría, o, por el contrario, individuos cargados de vicios que obstaculizan la vida en comunidad.

Aristóteles, en este contexto antiguo de temas y cuestiones que conciernen a la ética y su relación con las pasiones, ocupa un lugar privilegiado. Su pensamiento se orienta, precisamente, a la pregunta que se desprende de estas preocupaciones originales que eran relevantes en el mundo griego: ¿cómo debe vivir un hombre para alcanzar la eudaimonía? O, en otros términos, ¿cómo debería vivir un hombre para que podamos decir razonablemente de él que ha vivido de manera consumada? Así pues, para este filósofo, el objeto de investigación de la ética es la naturaleza de la vida buena para el hombre y los tipos de conducta correcta que conducen al logro de este fin último de la vida humana: la felicidad. Las pasiones, por ende, hacen parte de sus inquietudes morales.

Para comprender mejor esta postura, debemos analizar más a fondo los planteamientos del autor. Nos señala el filósofo: "Llamo pasiones al deseo, la cólera, el temor, la envidia, la alegría, el odio, la añoranza, la emulación, la piedad, y en general a todas las afecciones a las que son concomitantes el placer o la pena" (Aristóteles, trad. en 1985, 1105b20-23). Las emociones de vergüenza, temor, envidia, indignación son afecciones dolorosas. Por ejemplo, la vergüenza produce dolor por la pérdida de la buena reputación en la comunidad; solo los desvergonzados serían indiferentes a esta situación (Knuuttila, 2004).

Si bien Aristóteles reconoce la dimensión física o corporal de las emociones: calor en la sangre, sudor, frío, temblor, etc., en diversos fragmentos de su obra, se centra en una interpretación cognitivista en la que concede un lugar preponderante a la relación entre creencias y emociones, asunto que también será de especial relevancia para las teorías cognitivas contemporáneas de la emoción (Deigh, 1994). 
Para el filósofo antiguo, las emociones no son fuerzas animales ciegas, sino partes inteligentes y perceptivas de la personalidad, estrechamente relacionadas con determinadas ideas que tenemos acerca de los acontecimientos que vemos (modos de contemplar el mundo), y capaces, por tanto, de reaccionar ante nuevos estados cognoscitivos.

La interpretación fundamental que defiende Aristóteles es que las emociones están asociadas con ciertas creencias (doxai) y juicios (hypolepsis), lo que, en general, se denomina la dimensión evaluativa de las emociones: si alguien sonríe amigablemente y tú sientes cierta calidez o cercanía con esa persona, es porque evalúas esa sonrisa como un gesto de afecto. Esa evaluación, o appraisal, como suele usarse contemporáneamente, es vista como el factor central para la comprensión de las emociones desde una aproximación cognitiva (Oatley, 2004). Si retomamos los textos de Aristóteles (trad. en 1994, 1378a30), encontramos que la creencia de que hemos sido objeto de un agravio inmerecido, por ejemplo, excita nuestra ira y la creencia de que el sufrimiento de alguien es inmerecido despierta nuestra compasión (Retórica, 1385b13-19). Si tenemos la convicción de que alguien que conocemos guarda algo perverso en su interior, esta creencia obstaculizará la aparición de la piedad y probablemente provocará ira o indignación. Cuando creemos que algo es temible o dañino, inmediatamente padecemos en nuestro cuerpo las sensaciones del miedo (Aristóteles, Del Alma, trad. en 2010, 427b21-24). Este punto de vista será ampliamente retomado por algunas tradiciones actuales de la emoción que llevan a sostener las creencias como elementos necesarios y suficientes para que se den las emociones: si piensan $x$ entonces experimentarán la emoción $y$ (Bben-Ze'ev, 2004; Clore, 1994; Solomon, 2003).

En este contexto, resalta en el pensamiento de Aristóteles la idea de las emociones como formas de consciencia intencional, es decir, formas de consciencia dirigidas hacia un objeto o acerca de un objeto, esto implica que el objeto figura tal como se ve desde el punto de vista de la persona. La cólera, por ejemplo, no es una simple reacción corporal (calor en el cuerpo, ojos desorbitados, puños cerrados); para dar adecuadamente cuenta de ella, uno ha de mencionar el objeto al que va dirigida y por qué: "Cuando hacemos esto, caracterizamos el objeto tal como lo ve la persona que siente la emoción, tanto si esa visión es correcta como si no: mi cólera depende del modo como yo te veo y veo lo que has hecho, no del modo como tú eres realmente o de lo que tú realmente has hecho" (Nussbaum, 2003, p. 113). 
Según lo anterior, las emociones pueden calificarse adecuadamente de racionales o irracionales, y también de verdaderas o falsas según el carácter de las creencias que constituyen su base o fundamento. Si las emociones están ligadas a cierta forma como yo interpreto el mundo, entonces el cambio de creencias puede traer un cambio en las emociones. Si caemos en la cuenta de que las arañas que caminan por la casa no son venenosas, podemos llegar a experimentar serenidad o indiferencia cuando las vemos, pues nuestra creencia ha sido modificada al comprender que no hay ninguna sustancia que debamos temer en esos insectos. De igual manera, la cólera que sentimos contra alguien puede disminuir o desaparecer si caemos en la cuenta de que, en realidad, no había ninguna injuria por parte de esa persona, o que las expresiones que en algún momento utilizó en el diálogo de fondo no tenían ninguna intención explícita de ofendernos (Knuuttila, 2004).

Con estas nociones previamente establecidas, Aristóteles nos invita a reconocer la importancia que tienen las emociones en la comprensión moral. Las emociones, por ejemplo, pueden despertar el sentido de compasión al percatarnos del sufrimiento ajeno o del dolor inmerecido, también pueden provocar enojo cuando percibimos acciones contrarias a la virtud. Por este motivo, el Estagirita se aleja de aquellas doctrinas que buscan la insensibilidad frente al placer y dolor (apatheia) o las que proponen la imperturbabilidad del alma (la ataraxia estoica) como camino de vida. Por el contrario, estas tendencias son consideradas una deficiencia humana y hasta un vicio (Aristóteles, trad. en 1985, 1104b24-25).

Esta racionalidad de las emociones que podemos rastrear en la Ética nicomaquea se encuentra estrechamente vinculada con la idea de virtud moral entendida como búsqueda del término medio según el hombre prudente: las emociones deben ser adecuadas a los objetos y a las situaciones que las provocan y deben ser experimentadas de modo apropiado a partir de criterios de racionalidad como la sensatez. Por ejemplo, es insensato temer a todo, o asustarse por todo, que incluye una plácida ardillita en el bosque. En este caso, se observa que son emociones inadecuadas o desproporcionadas con respecto a la situación u objeto que las provoca; también se pueden experimentar de manera inapropiada, por ejemplo, un desenfreno bestial de violencia frente a una situación en la que una persona se siente ofendida por alguien que ha cometido un agravio insignificante o una acción que no se corresponde con la venganza o con conductas de retaliación crueles (Dow, 2015; Trueba, 2009). 
Lo anterior nos lleva a comprender cómo las pasiones, en tanto afecciones, no son dignas de elogio o censura, en tanto sí lo son según la manera y las circunstancias en las que son experimentadas por las personas (Aristóteles, trad. en 1985, 1105b31-110). No indignarse por la injusticia cometida al prójimo, por ejemplo, puede resultar una actitud servil propia de esclavos. El que no siente temor ante nada puede estar más cerca a la demencia que a la virtud. Ser esclavo, según Aristóteles, es estar a disposición de otro, ser el instrumento vivo del proyecto de vida de otra persona, carecer de la capacidad íntegra de elegir por uno mismo. A esa condición puede rebajarse un individuo que no honra los compromisos que tiene con su familia o amigos al no reaccionar adecuadamente cuando la situación lo amerita. La indignación se presenta entonces, por ejemplo, como una motivación para defender las cosas amadas, presumiblemente porque se considera esta reacción como un reconocimiento de que el objeto dañado tiene importancia $y$, sin ese reconocimiento, uno no tendría ninguna razón para defenderlo (Knuuttila, 2004). Sentir una indignación proporcionada es, por tanto, una actitud adecuada, siempre y cuando surja en el momento propicio y con la persona correcta. Es claro entonces cómo para Aristóteles las emociones garantizan el respeto y la adecuada relación con los demás en la comunidad política, por eso, están vinculadas a la vida virtuosa y la formación del carácter.

Ahora bien, en opinión de Aristóteles, las emociones no son siempre correctas, de la misma manera que tampoco lo son siempre las creencias en las que se fundamentan. Han de ser educadas y armonizadas con una visión apropiada de la vida buena o florecimiento humano. Se trata de una tarea de entrenamiento, de modulación y de habituación de las emociones que el agente debe hacer como parte de su carácter moral. Pero, una vez educadas, no son esenciales simplemente como fuerzas impulsoras de la acción virtuosa: son también ejercicios de reconocimiento de la verdad y del valor. Lo que esto significa es que, si la acción aparentemente correcta se eligiera sin la motivación y reacción emotiva adecuada, no contaría, para Aristóteles, como una acción virtuosa: una acción es virtuosa solo si se hace de la manera como la haría una persona virtuosa. El reconocimiento de algunas verdades éticas es imposible sin la emoción, de hecho ciertas emociones comportan esencialmente esos actos de reconocimiento (Nussbaum, 2003).

Después de analizar esta concepción aristotélica de las emociones, podemos sacar algunas ideas en claro sobre estos primeros estudios acerca de las pasiones. Para el 
Estagirita, la filosofía es moldeadora de almas para la comunidad política. La filosofía puede ocuparse de los discípulos de uno en uno y perfeccionar su capacidad para llevar una vida buena mediante el cultivo de la virtud, lo cual conlleva el manejo apropiado de las emociones. Los seguidores de Aristóteles, por consiguiente, no persiguen su propia eudaimonía o felicidad, sino también la de los demás mediante la modulación de las emociones de acuerdo con personas, lugares y situaciones. Cuando un individuo se habitúa a reaccionar emocionalmente con equilibrio y prudencia, entonces adquiere un carácter moral bello y floreciente, es decir, una forma de vida que es valiosa y digna de ser admirada por todos (Trueba, 2009).

Los argumentos expuestos nos permiten comprender cómo la propuesta de Aristóteles en torno a las pasiones gira alrededor del contexto y el juicio equilibrado de cada situación. Las pasiones no adquieren un valor negativo, sino de acuerdo con la situación específica en la que actúe un individuo. La prudencia, o el punto medio, es el criterio para establecer la adecuación de una determinada conducta. La fuerza o la ira excesiva de un soldado es condenable, al igual que la temeridad exagerada, pero es innegable que en situaciones de combate debe haber una pasión que le garantice el éxito en la guerra. Una emoción fuerte puede, por consiguiente, ayudar a que el sujeto tenga la motivación o el impulso necesario para llevarla a cabo. Con otras palabras, lo fundamental de la propuesta aristotélica es que la emoción es el aspecto que acompaña y otorga la fuerza a las diferentes conductas generadas por creencias y por el prudente reconocimiento de las distintas demandas del contexto.

En Aristóteles, las valoraciones de racional e irracional se establecen sobre el tipo de creencias y no sobre dimensiones dicotómicas en la naturaleza humana (pasiónrazón), por tal motivo su pensamiento se mantuvo alejado de una visión negativa de las pasiones, que ya había sido formulada previamente por Platón en su célebre visión antropológica de alma y cuerpo. Pero los filósofos posteriores a Aristóteles tomaron otros rumbos de reflexión y ayudaron a establecer los presupuestos de un antagonismo entre razón y emoción que ha perdurado hasta el día de hoy. Las emociones se convirtieron en esas dimensiones condenables que nos alejan de nuestros ideales de perfección y de vida buena. La emoción bajo estas perspectivas adquirió un sentido valorativo negativo. Veamos algunas de estas posturas. 


\section{Epicureísmo y emoción}

El epicureísmo es una escuela filosófica helenística que recibe su nombre de Epicuro de Samos (341-270 a. C.). Para este pensador, la filosofía tenía una función eminentemente práctica: debía servir como medicina del alma, de ahí su frase "vana es la palabra del filósofo que no cura los sufrimientos del ser humano". En su contexto, la labor filosófica se entendía como una terapia que permitía enfrentar las grandes enfermedades del alma fundamentalmente ligadas a las pasiones. Así pues, para curar al ser humano de esos estados interiores, primero, debía liberar al individuo de las turbaciones que le inquietaban y, luego, conducirlo a la conquista de la felicidad.

Para lograr su objetivo terapéutico de curar y perfeccionar el alma, Epicuro fundó su célebre escuela filosófica llamada el jardín. Se trataba de un lugar separado de la sociedad con sus propias leyes y funcionamiento. La comunidad del jardín era autónoma, cosmopolita y plural. Se cuenta que, incluso, había mujeres que participaban de las lecciones del maestro, costumbre que no era frecuente en el mundo griego antiguo. A diferencia del liceo de Aristóteles, su comunidad no era un colegio o instituto de investigación, sino una compañía de amigos que viven conforme a unos principios comunes, retirados de la vida civil. Epicuro encarnó en su estilo de vida todo el conjunto de ideales morales que predicaba y escribía, de tal forma que, más que un maestro académico que ofrecía una instrucción formal, se trataba de un hombre que personificaba unos valores que terminaban siendo persuasivos para sus seguidores.

Para entender la doctrina de Epicuro acerca de las pasiones, conviene tener en cuenta algunas consideraciones morales que configuran su pensamiento. Al igual que Aristóteles, considera la pregunta por la felicidad o eudaimonía como una cuestión central en la vida humana, pero orienta esta indagación en otro sentido. Epicuro identifica la pregunta por la felicidad con la pregunta por el fin último que persigue nuestra naturaleza. El término recupera en él el sentido primario de desenlace exitoso de una actividad y se identifica con el concepto de bien natural, de bien dado, configurado y delimitado por una naturaleza que actuaría en forma mecanicista. Esta consideración lleva al filósofo a identificar el bien que persigue nuestra naturaleza humana con el placer. El principio ético supremo es el placer, es lo único conveniente a nuestra naturaleza, de modo que el dolor es su contrario.

Podemos ahora establecer algunos contrastes con el Estagirita. Si en Aristóteles el fin al que se deberían orientar los esfuerzos de la naturaleza humana era la búsqueda 
de la belleza y las más elevadas reflexiones sobre la verdad y la justicia, en Epicuro la naturaleza humana estaba orientada por la búsqueda del placer, un placer que era entendido como reacción a una serie de valores imperantes en la sociedad de su época. La felicidad estaría en la búsqueda de unos placeres que eran presentados como naturales y como los que alejarían al hombre de deseos vanos y de necesidades falsas propias de la sociedad. En estas ideas radica el núcleo del pensamiento de Epicuro.

La bondad del placer no requiere demostración. Epicuro da por supuesto que los hombres, al igual que todos los seres vivos, persiguen el placer y evitan el dolor. Dice Epicuro que "el placer es el bien primario e innato". Hoy en día, podríamos decir que estamos genéticamente programados para buscar lo que ha de causarnos placer y evitar lo que ha de causarnos dolor, esta sería una correcta interpretación de su punto de vista. El placer y el dolor están relacionados uno con otro, no como contrarios, sino como contradictorios. Su análisis descansa en el supuesto de que la condición natural o normal del hombre como ser viviente es la de un bienestar corporal y mental, y que esta condición es de hecho satisfactoria (Long, 1975).

Ahora bien, su doctrina no va dirigida a promover una vida licenciosa de placeres, como a veces se ha considerado. El beber, la buena comida, el sexo y demás actividades similares son fuente de placer, pero afirma el filósofo que los placeres que tales actividades producen han de ser rechazados como fines, porque no constituyen una sosegada y estable disposición del cuerpo y de la mente. Es la liberación del dolor lo que mide los méritos relativos de las diferentes actividades, por eso, hace incluso una crítica al lujo y al libertinaje sexual.

Este contexto ayuda a entender la figura de Epicuro como maestro y médico que viene a curar la turbación del alma generada por creencias falsas acerca del mundo y del valor de las cosas. Epicuro, como sabio que proponía un particular modo de vida, pensó que podía rastrear las causas de la infelicidad humana en creencias erróneas propias de la sociedad, creencias acerca de los dioses, del destino del alma, así como de los objetos de la vida que poseen verdadero valor. En última instancia, toda su enseñanza va enderezada a desacreditar tales creencias y sustituirlas por aquellas que él sostiene como verdaderas.

Ahora bien, el concepto de placer, según Epicuro, está estrechamente relacionado con un análisis del deseo, y los deseos están en estrecho vínculo con las pasiones. En 
la Carta a Meneceo afirma el maestro que el deseo de alimento y vestido es natural y necesario. El no poder satisfacer ese deseo es fuente de dolor. Pero argumenta Epicuro que no es necesario ni natural desear tal alimento o vestido antes que tal otro para eliminar el dolor que se siente por la falta de alimento o de vestido. Por ejemplo, desear un tipo específico de pescado o manjar suculento porque se tiene hambre. De aquí que Epicuro abogue por la vida sencilla, basándose en que nosotros mismos nos creamos dolores innecesarios al buscar satisfacer los deseos por medios desproporcionados (Pasquali, 1970).

Estas ideas aquí expuestas ayudan a comprender mejor cómo se explican las pasiones en el epicureísmo. De forma similar a Aristóteles, las pasiones o emociones son estados del alma vinculados con las creencias que vamos desarrollando acerca del valor que tienen ciertos bienes externos y los deseos que se suscitan en nuestro interior para conseguir aquello a lo que le damos gran relevancia; se trata, por tanto, de un problema relativo a valores (Fitzgerald, 2008).

Los seres humanos damos un gran valor a bienes externos que no están bajo nuestro control pensando que proporcionan la verdadera felicidad. Pero Epicuro manifiesta que ni libaciones, ni festines reiterados, ni gozar de mujeres, ni todas las demás cosas que proporciona una gran fiesta engendran una vida agradable. La gente corre frenéticamente tras el dinero, la fama, las delicias culinarias, el culto a la belleza y el amor pasional convencidos por la cultura misma, por la sociedad, que esas cosas tienen mucho más valor del que tienen en realidad para la felicidad. Por todos lados, señala Epicuro, vemos a seres humanos víctimas de falsas creencias que los llevan a buscar con afán montañas de dinero, completamente convencidos de que no pueden vivir sin sus objetos finos importados, sin su posición social, sin sus amantes. Todo un cúmulo de creencias que son fruto de la enseñanza que recibieron del contexto social y poco cercanas a los verdaderos valores.

Como se puede entrever, las creencias erróneas son un asunto que está en la sociedad o cultura en la que nacemos y crecemos. Por ejemplo, el deseo de vestido es natural y necesario, pero la sociedad nos hace creer que los vestidos lujosos y costosos, o de tal marca, son el mejor medio para satisfacer este deseo natural, de donde proviene una gran turbación si no tenemos los medios para alcanzar aquello que deseamos. Este deseo por tener tal o cual vestido puede generar la pasión de envidia o la tristeza al sentir que estamos por debajo del umbral de lo que cualquier ciudadano debería tener. 
Las personas no comprenden, por tanto, que la prudencia es la virtud más deseable porque nos proporciona la verdadera paz mental. Es un medio de alcanzar el mayor placer, pues nos habilita para dejar de lado aquellos placeres que implican un mayor dolor. Así pues, para el epicureísmo, la sociedad está enferma, es una colectividad de hombres y mujeres que valoran el dinero y el lujo por encima de la salud del alma: deseamos ansiosamente estos bienes y este vano deseo excita la ira, la envidia, la vergüenza, y demás pasiones del alma. Se trata de una sociedad cuyas desviadas enseñanzas acerca del amor y del sexo convierten a la mitad de sus ciudadanos a deificar y a odiar a la vez todas sus posesiones. Estas reflexiones muestran el talante de Epicuro como un protopsicólogo en la Antigüedad: "Se trata de su percepción de que las falsas creencias que turban nuestra vida no se hallan todas en la superficie del yo, listas para ser objeto de escrutinio crítico y dialéctico. Esas falsas creencias penetran profundamente en el alma, ejerciendo a menudo su deletérea influencia por debajo del nivel de la conciencia” (Nussbaum, 2003, p. 175).

Las ciudades se convierten, por tanto, en conglomerados de seres humanos envenenados o contagiados unos a otros por valoraciones equivocadas que los impulsan a refugiarse cada vez más en esos vanos deseos de posesión, dominio y explotación. Como sucede con cualquier infección, las creencias erróneas se expanden de boca en boca, de reunión en reunión, en las familias, en las instituciones educativas y en la atmósfera de ideas que respira el hombre común y corriente en la calle (Pasquali, 1970). Finalmente, se observa que la gente no sabe en el fondo lo que cree, lo que quiere y le motiva, y por tanto tienen una existencia que va y viene según los deseos del momento, sin una reflexión profunda que medie entre sus deseos y lo verdaderamente valioso.

El dinamismo de las pasiones del alma está ligado, por tanto, a la fuerza de los deseos, y la terapia de curación que se practica en la escuela del jardín apunta a una forma de paideia, o educación liberadora de los deseos. El objetivo final será alcanzar la ataraxia o ausencia de dolor y de perturbaciones como consecuencia del trabajo interior que realiza el discípulo en torno a la modificación de las creencias y de los vanos deseos que desencadenan las más intensas pasiones. Aquí es importante reconocer la asociación entre la virtud y el placer. La conexión necesaria entre el placer y las virtudes se debe a la noción de que el placer requiere, para su logro, un razonado aquilatar de las ventajas y desventajas relativas de un acto o situación dados, una capacidad para controlar deseos cuya satisfacción pueda envolver dolor para el agente, liberación del temor al castigo y otros tales (Long, 1975). 
Para lograr su objetivo terapéutico, Epicuro acude a curiosas acciones didácticas. En su escuela, los discípulos deben memorizar y repetir los kyriai doxai, o compendios de las cartas que contienen las enseñanzas del maestro. La finalidad es interiorizar por medio de fragmentos cortos la enseñanza de modo que se vuelva poderosa y logre contrarrestar la falsa creencia. En estas cartas, hay recomendaciones para librarse del apego a los bienes externos y a los vanos deseos que se desprenden de este apego. También hay insistentes recomendaciones que develan un conocimiento de lo que hoy en día podemos llamar "las capas inconscientes de la motivación", asunto que es de vital importancia para comprender por qué nos dejamos arrastrar por objetos que carecen de auténtico valor para la felicidad (Cooper, 1999).

Independiente del ideal de vida que propugna Epicuro, y de su terapia de protesta contra valores propios de una cultura, queremos resaltar en este punto el contenido valorativo del concepto de pasión que se reedita en la obra del fundador del jardín. Si nuestro filósofo plantea una forma de vida adecuada (a la que considera más propia de la naturaleza humana), las ideas que se opongan a ella son calificadas de falsas creencias y de espacios de irracionalidad y de expresiones pasionales. La emoción nuevamente se expresa asociada a ciertas formas de vida y de comportamiento. Las formas de vivir condenadas por Epicuro son explicadas en su visión filosófica como expresiones de lo emocional. Esto nos ayuda a entender cómo la emoción en la Antigüedad es comprendida de manera insistente como un sinónimo de lo condenable, de todo aquello que atenta contra la naturaleza humana, contra su felicidad y contra la razón, que, en este contexto helenístico, asume la significación valorativa de conducir al ser humano por aquellos caminos que auténticamente aseguran su bienestar.

Pero si bien en el epicureísmo la emoción es tan solo la explicación del porqué seguimos ideales de vida reprobables, en el estoicismo la emoción se independiza de toda forma de vida particular para convertirse ella misma en algo condenable. Veamos la radicalidad de esta última formulación de la filosofía griega.

\section{Los estoicos y la extirpación de las pasiones}

El estoicismo es la escuela de pensamiento y terapéutica del alma que más influencia ha tenido en la filosofía occidental. Se trata de una forma de vida y un conjunto de enseñanzas en que confluyen un amplio número de hombres cultivados en el mundo greco-rromano, y su impacto no quedó confinado a la Antigüedad clásica. 
El estoicismo tuvo un primer periodo fundacional con Zenón de Citio, Cleantes y Crisipo, que establecieron las bases de la doctrina estoica; un segundo periodo en el que las enseñanzas de estos maestros se difundieron en Roma, y un tercer periodo que se denomina estoicismo nuevo o imperial. Se trata, por consiguiente, de una escuela de pensamiento que se extiende aproximadamente desde 332 a. C. hasta el siglo III d. C. Muchos de los Padres de la Iglesia fueron profundamente influidos por el estoicismo, también autores modernos como Baruch Spinoza y Immanuel Kant fueron deudores de los estoicos. Incluso, actualmente, todavía resultan de gran interés las doctrinas estoicas en torno a diversos aspectos que configuran la existencia humana: la ética, la física, la política, las emociones.

Los tratados estoicos acerca de las pasiones prefiguran con gran autenticidad diversos temas que serán retomados por la filosofía y psicología contemporánea de las emociones, de ahí su valor para comprender algunas corrientes actuales que defienden, por ejemplo, un vínculo fuerte entre emoción y cognición, y una relación estrecha entre la dimensión emocional del ser humano y la vida moral. Estos aspectos los analizaremos a continuación con mayor detenimiento.

En el Mundo Antiguo, los estoicos se destacan por el análisis detallado que hicieron de las pasiones o las emociones entendidas como vivencias que afectan decisivamente nuestra manera de ser en el mundo. La visión que estos autores desarrollan de las pasiones está indisolublemente unida a su concepción moral que arranca del mismo punto que todas las morales griegas: la búsqueda de la felicidad y las virtudes que conducen a este fin último de la existencia humana. Así pues, para comprender la manera como los estoicos trataron las pasiones, primero, debemos partir de su idea de felicidad.

La eudaimonía o felicidad es un fin último que los seres humanos deseamos alcanzar, siempre actuamos buscando un bien, ya sea ganar dinero, vivir tranquilos u obtener fama y reconocimiento, pero detrás de todos estos objetivos que, o solo tienen apariencia de bienes o son en realidad un medio para alcanzar otro objetivo, existe un bien que se busca por sí mismo: la felicidad como bien supremo. Este bien deseable por sí mismo y que no se subordina a ningún otro se alcanza por el ejercicio de la virtud. Para los estoicos, solo la virtud merece ser elegida por sí misma, y la virtud por sí sola basta para una vida humana completamente buena, es decir, para la eudaimonía. 
La virtud es algo que no se ve afectado por las contingencias externas. Las cosas que no quedan plenamente bajo el control del agente, tales como la salud, la riqueza, la ausencia de dolor, el buen funcionamiento del cuerpo, entre otras, carecen de valor intrínseco y su relación con la eudaimonía se observa como algo que no es necesario ni fundamental. En resumen, "si prescindimos de todas esas cosas, si imaginamos una persona sabia viviendo en las peores circunstancias posibles, esa forma de vida, si es orientada por la virtud, permanecerá siempre como una vida valiosa, apetecible y envidiable para cualquier ser humano" (Nussbaum, 2003, p. 78).

La virtud no es, pues, definida por aquellas consecuencias que ella consiga promover en el mundo, sino por un talante o estilo de comportamiento derivado, necesariamente, de una disposición de manera perfecta entonada con la racionalidad de la naturaleza. Por ejemplo, como todos los hombres, el sabio estoico se halla predispuesto a mirar por su salud y su hacienda. Mas él no mira tales bienes como cosas deseables en sí mismas. Las elige si, y solo si, su razón le dicta que tal es la acción recta a cumplir. La acción recta a cumplir es aquella que concuerda con la virtud, y esto equivale a decir que concuerda con la naturaleza de un ser racional. De acuerdo con esto es que se señala en la doctrina estoica que solo la virtud posee valor absoluto o intrínseco (Long, 1975). El sabio hará un buen uso de la pobreza si esta le sale al paso; por el contrario, un necio siempre podrá usar mal la riqueza. Mas la riqueza no es un constitutivo de la virtud. Moralmente hablando, riqueza y pobreza son indiferentes, pues no hace diferencia en el valor moral (o bienestar) de un hombre que sea rico o pobre.

Según lo anterior, la felicidad para el estoico se encuentra, sobre todo, en la libertad del hombre que no se liga más que a lo que depende de él; por tanto, a lo que cae bajo el imperio de su voluntad, y frente a todo lo demás: contingencias materiales, opinión de los otros, buena o mala fortuna, practica la más perfecta indiferencia. Esta postura contrasta con la búsqueda del placer de Epicuro. El placer no debe entrar en cuenta, pues el verdadero bien debe ser seguro y estable, y estas cualidades le faltan al placer. No queda más que "echarlo lejos del lugar de los verdaderos bienes", como bien diría Epicteto en sus Máximas (Leclercq, 1956). Así pues, la felicidad no ocupa, entre los estoicos, el mismo lugar que en Aristóteles y Epicuro. Aristóteles definía la eudaimonía como la actividad del alma en concordancia con la virtud, mas reconocía que ello requiere una adecuada provisión de recursos: posesiones, salud, y otros bienes. Para los estoicos, por el contrario, solo la virtud es indispensable y suficiente para la eudaimonía. Esta reflexión resulta importante porque tendrá una notable influencia 
en la manera como los estoicos analizan las pasiones en relación con ciertas creencias que tenemos acerca de lo que nos conduce a la felicidad.

Los estoicos consideran que los seres humanos están perturbados por las pasiones y las enfermedades del alma que se desprenden de ellas, por eso, es una filosofía que se ofrece a modo de medicina o terapia para curar esos estados negativos por los que todos en algún momento pasamos. Lo significativo de las ideas estoicas en relación con las emociones consiste en la visión cognitivista que desarrollan al comprender estos fenómenos humanos bajo la idea de un tipo de "desviación de la inteligencia".

Se atribuye a Crisipo un viejo texto Sobre las pasiones que recoge diversas enseñanzas estoicas al respecto; este es un trabajo recuperado doxográficamente por Diógenes Laercio y otros autores como Galeno que nos da cuenta sobre cierta concepción antigua de la emociones entendidas como creencias o juicios de valor (Long, 1975). Según la doctrina estoica, las emociones tienen que ver con la forma en que se valoran objetos y situaciones con una valencia buena o mala y en relación con un tiempo presente o futuro. Si es sobre un objeto o acontecimiento del presente, el juicio implicará emociones de placer (hedoné) o dolor (lupé), y si es acerca del futuro, implicará una emoción de apetito (epithumia) o miedo phobos (Knuuttila, 2004).

Crisipo, por tanto, introduce la idea de las emociones (pasiones) como un tipo de creencia (doxa) o juicio evaluativo (krisis) que determina una propiedad buena o mala en los objetos: esto es $x$, y $x$ es un gran bien o un gran mal y, por ende, es apropiado reaccionar a $x$ de determinada manera emocional. ${ }^{2}$ El miedo, por ejemplo, es un juicio de valor sobre un mal inminente que parece ser intolerable.

Para Crisipo, la gente común y corriente asigna un valor intrínseco a un sinnúmero de bienes externos, por ejemplo, a la amistad y el amor, bienes que por su naturaleza son inestables y fuera de nuestro control. La mayoría de la gente, además, se ve a sí misma como seres sociales que desean ser reconocidos de determinada forma en la comunidad a la cual pertenecen, por tal motivo la pérdida de la buena posición social

2 Siguiendo las interpretaciones de Nussbaum, "Crisipo parece haber usado tanto la palabra doxa, habitualmente traducida como creencia u opinión, como la palabra Krisis, habitualmente traducida por juicio. A veces utiliza también el término hypolepsis o suposición en ejemplos particulares. Dado que los estoicos raramente son cuidadosos con respecto a especificar a qué tipo exacto de actividad cognitiva se refieren, esto no representa problema alguno para su argumento" (2003, p. 456). 
o de privilegios políticos a los que están acostumbrados hace que desarrollen en su interior la creencia de que se ha perdido algo intrínsecamente valioso (Graver, 2007). La mayoría también cree que la buena vida humana no puede alcanzarse sin una cierta cantidad de alimentos, dinero, vivienda, salud corporal, belleza, honores y el amplio disfrute del placer sexual, objetos que consideran necesarios para la eudaimonía. Estas ideas serán justamente el objeto de negación para los estoicos, pues, para esta escuela de pensamiento, las virtudes son consideradas estados del alma que no son afectados por las contingencias mundanas.

¿Cómo acontece esto en nuestra mente? Se trata de un proceso evaluativo en dos momentos: primero tenemos un evento que llama nuestra atención y crea una impresión, es decir, vemos la situación de determinada manera, luego aceptamos o abrazamos esa representación o apariencia como verdadera, nos comprometemos con ella y hacemos un juicio que genera una emoción (Nussbaum, 2003). Séneca, uno de los más influyentes estoicos romanos, en Sobre la ira, aclara este proceso introduciendo la idea de "primeros movimientos o situaciones preliminares a las emociones". Frente a una situación de agravio, por ejemplo, hay un primer movimiento en la mente involuntario que se puede describir de la siguiente manera: "Pienso que estoy siendo injuriado y quieren humillarme", es un efecto natural sensitivo corporal, una agitación inicial de la mente que puede causar cierta reacción, como fruncir el ceño y apretar los dientes, pero no es la emoción real. Luego, viene un segundo movimiento en el que hay un asentimiento de la mente, un juicio y una intervención de la voluntad que genera una determinada reacción. El problema fundamental de las pasiones radica en el asentimiento que se introduce entre la representación y la tendencia o inclinación. Asentir, por consiguiente, implica haber realizado una apropiación, la cual es posible porque las representaciones se acompañan de una percepción de ella misma que manifiesta su relación o no con nosotros (Long, 1987).

Este segundo movimiento es propiamente la emoción porque da cuenta de la relevancia que le hemos dado a la situación en que nos encontramos. Según el estoicismo, este asentimiento conduce a un movimiento irracional del alma como resultado de una adhesión a una mera creencia o suposición que implica una valencia buena o mala en la forma como valoro las situaciones. Aquí se percibe, por tanto, una concepción distinta del tratamiento que los epicúreos realizaron de las pasiones. Para los estoicos, son estos juicios erróneos contrarios a la razón, los que realiza cada individuo en una 
situación determinada, los que dan lugar a las pasiones, mientras que para los epicúreos son ciertos valores sociales o culturales a los que se vincula la gente de manera equivocada los que exacerban los deseos que suscitan las pasiones. Para los epicúreos, el problema de las pasiones recae en los vanos deseos que se persiguen, porque la civilización los hace ver como los mayores bienes humanos: la sociedad valora la riqueza, el estatus, los atributos físicos y el poder político, entre otras cosas, y muchas personas persiguen frenéticamente esos bienes superfluos propuestos por la sociedad porque erróneamente creen que conducen a la felicidad. Para el estoico, las pasiones no dependen en sentido estricto de los valores sociales (aunque estos pueden tener cierta influencia en la vida de las personas), sino en el proceso cognitivo valorativo que cada individuo desarrolla frente a sucesos, personas y cosas que hacen parte de su entorno. De igual manera, en contraste con Epicuro, el estoico no considera el placer como algo bueno, ni el dolor como algo malo. El sabio estoico no es insensible a las sensaciones dolorosas o placenteras, mas estas no conmueven su alma en exceso, más bien queda impasible ante ellas.

Para Séneca, cualquier persona es susceptible de experimentar un primer movimiento, pero en el asentimiento y en la reacción puede entrar la voluntad corrigiendo el juicio erróneo que se da en la respuesta emocional. Tal es el caso del dolor: un sabio estoico puede dar muestras de que ha sido afectado por algo que causa dolor, pero puede tomar distancia para no dejarse dominar por la emoción de tristeza que seguramente emergerá si asiente a ese estímulo (Knuuttila, 2004).

Al concebir las emociones de esta manera, los estoicos consideran que los padres, las personas que nos cuidan durante la infancia, los pedagogos y las mismas ideas presentes en la sociedad a la que pertenecemos pueden generarnos falsas creencias que influyen en la aparición de estados emocionales descontrolados. Las costumbres que nos enseñan de niños para evitar el frío, el hambre, el dolor, las que nos persuaden de que todo dolor es un mal, y lo mismo las opiniones que desde niño oímos en derredor nuestro durante toda la educación, desde las expresadas por las nodrizas hasta las de los poetas y pintores, todas elogian el placer y las riquezas. Esta es la razón por la que Crisipo llega a pensar que las emociones son desobedientes a la razón y contrarias a la naturaleza al dárseles a los objetos y bienes externos (personas, dinero, fama, posición social, belleza, etc.) un peso o valor más allá del apropiado, esto es, un juicio impulsivo acerca de cosas presentes o futuras: los juicios emocionales son errores del pensamiento, juicios falsos dictados con ligereza o concepciones inadecuadas acerca 
de la realidad que desencadenan un cúmulo de estados que ciegan y desorientan la recta razón (Nussbaum, 1987).

En este contexto, la existencia de la pasión ofrece a la psicología estoica un problema difícil: si según los estoicos toda la sustancia del alma es razón, ¿cómo puede existir en ella lo irracional, que sería el campo de las pasiones? Crisipo examina esta situación admitiendo que estos juicios se introducen en el alma por una situación de "debilidad del alma" que desorienta la recta razón, es decir, una especie de falla en la misma facultad racional (o razón viciada) que lleva a asentir estas creencias débiles que conforman las pasiones.

Un ejemplo claro de esta situación lo podemos apreciar en las personan que tienen la creencia de que el dinero es el mayor bien que un ser humano puede tener e, incluso, suponen que la vida no es digna de ser vivida por el hombre que lo ha perdido; esta sola creencia puede generar tristeza en aquel que le da a este objeto un valor elevado. La ira, por su parte, es el juicio de que se ha cometido contra uno o un ser querido una grave injusticia, afrenta o humillación y, por tanto, debe ser castigada o vengada. Una vez se ha introducido esta creencia valorativa concreta en nuestra mente, sentimos el calor en la sangre, el aceleramiento del corazón, el temblor en el cuerpo y demás sensaciones que delatan nuestra cólera. El celoso siempre desarrolla la valoración de que su amado o amada está realizando o puede realizar de manera inminente actos secretos de infidelidad o deslealtad a su amor, por eso, ve con alteración cada salida, retardo y demás situaciones que se pueden presentar en la cotidianidad como un indicio de que la otra persona está buscando un nuevo ser para amar (Graver, 2007).

Sin negar la existencia de un tipo de falla en la razón (lo que es visto como una sinrazón o razón viciada dentro del estoicismo), los estoicos insisten en la importancia del juicio para indicar cómo la pasión depende de nosotros. Crisipo, por ejemplo, aclara el papel de los juicios de conveniencia en el surgimiento de ciertas pasiones. El juicio o la creencia de que es bueno y justo entregarnos al disgusto cuando muere un pariente genera dolor, llanto, tristeza y se adopta el luto, pero, si meditamos acerca de tal juicio, con una serie de máximas razonadas, constataremos que la razón puede apartarnos de tales inclinaciones exageradas. Con el tiempo, si no se atiende terapéuticamente este tipo de juicios, las pasiones que son de por sí pasajeras e inestables se transformarán en enfermedades del alma que llegan a fijarse y hacerse difíciles de extirpar (Bergua, 1936; Graver, 2007). 
Según lo anterior, solo el sabio u hombre de bien es criterio de racionalidad dado que solo él posee recta razón. Los demás hombres no tienen un juicio o logos asentado, por eso, están sometidos a cambios súbitos y a fluctuaciones interiores. Por ejemplo, hay individuos que son dados a afirmar que el dolor es algo muy malo, lo cual acude a su mente y este juicio es acompañado de una reacción corporal cuando el dentista intenta arreglar sus dientes (Long, 1975). Esta ausencia de correspondencia con la recta razón nos marca y distingue como "necios" u hombres viciosos.

El sabio estoico reconoce, por tanto, que los juicios con los que se identifican las pasiones son falsos, pues las cosas externas no tienen tanto valor, en realidad carecen por completo de valor ético intrínseco, por tal motivo tiene la capacidad de sobreponerse a ese cúmulo de creencias erróneas denominadas pasiones tratando de llevar una vida serena (ataraxia) frente a todo lo que acontece en este mundo. Los estoicos reconocen, por tanto, el aspecto cognitivo de las emociones, pero niegan su papel positivo tanto en la vida teórica como en la vida práctica. Vislumbramos entonces el radical desapego del sabio estoico en todas las dimensiones: un desprendimiento que llega a concebir al familiar muerto bajo la idea tranquila de "ya sabía que solo era un simple mortal”. Su medicina es, por consiguiente, una terapia acerca de las pasiones y de los apegos que generan sufrimiento, perturbación y angustia en el alma. Nussbaum reconoce en esta comprensión estoica de las pasiones lo que denomina una auténtica "inteligencia de las emociones", es decir, creencias o juicios que nos hacen implicarnos en el mundo de determinada manera. Al respecto, nos indica la filósofa:

Los estoicos nos ofrecen, pues, una visión precisa de las pasiones: las emociones no son simplemente ciegas erupciones de afecto, sacudidas o sensaciones que se reconocen y distinguen unas de otras por la cualidad sentida en cada una de ellas. A diferencia de apetitos como la sed y el hambre poseen un importante elemento cognitivo. Las emociones encarnan maneras de interpretar el mundo, los sentimientos que las acompañan van ligados y se apoyan en creencias o juicios que constituyen su base o fundamento, de tal manera que la emoción en su conjunto $[\mathrm{sic}]$ pueden calificarse adecuadamente de verdaderas o falsas, así como de racionales o irracionales, según la valoración que hagamos de la creencia que la fundamenta. Las creencias valorativas sobre las que descansan las emociones entrañan la atribución de un alto valor a vulnerables bienes externos que no están bajo nuestro control, pero que influyen poderosamente 
sobre nuestra percepción del mundo o en nuestra manera de interpretar el mundo. (2003, p. 459)

De acuerdo con esto, el mundo de la vida se muestra como un campo de objetos a los cuales investimos con un tipo de valoración que termina afectando nuestra conducta, por ejemplo, "cuando vemos [a] una persona molesta y la evitamos cambiando de camino, actualizamos la creencia valorativa que teníamos sobre ella (persona molesta), evaluamos la situación (prefiero encontrarme con personas no molestas), y actuamos en concordancia con la creencia y la evaluación: es mejor cambiar de camino" (Villamil, 2011, p. 195).

Dado que la creencia es el fundamento de la emoción, estas se pueden modificar en tanto exista una modificación de la creencia. Para comprender mejor este argumento, debemos tener claro los siguientes aspectos que Nussbaum (2008) analiza de los planteamientos estoicos acerca de las creencias y de las pasiones:

a. La creencia es necesaria para la pasión.

b. La creencia es un elemento constitutivo, necesario, de la pasión.

c. La creencia es suficiente para la pasión.

d. La creencia se identifica con la pasión.

Como vamos analizando, el problema está en el asentimiento que damos a una falsa creencia. Para el estoicismo, la enfermedad del alma radica en que damos un valor elevado a las cosas, en que pensamos que las cosas que aparecen ante nosotros son mucho mejores de lo que son; en definitiva, pensar que son lo más importante. En esta actitud, radica la falsa creencia, pues el estoicismo propone que los bienes externos carecen de valor alguno para la virtud y la eudaimonía. Si esto es así, podemos vislumbrar la medicina estoica: una persona que deje de preocuparse por los bienes externos estará libre de pasiones. Todas las creencias-emociones comparten un campo temático determinado, y deben identificarse y definirse en relación con dicho campo temático. Si reconocemos este campo temático, estamos mejor pertrechados para saber qué es lo que nos está motivando emocionalmente y cómo podemos extraerlo (Fitzgerald, 2008). Nuevamente, traemos el ejemplo con el dinero: el que está triste 
por su condición económica está motivado por la creencia en el valor intrínseco del dinero. Su idea según la cual el dinero lo es todo, o es signo de felicidad, no lo deja en paz y lo conduce al terreno negativo de la desesperación porque carece de él. La terapia estoica implicará una modificación de esa falsa o engañosa creencia que lo atormenta y no lo deja llegar a la ataraxia o imperturbabilidad.

Séneca añade en sus escritos Sobre la ira una serie de detalles sobre lo que la apariencia de las cosas puede generar en nosotros. A veces, la presencia de una representación puede suscitar una reacción, incluso, cuando la propia apariencia no es aceptada ni interiorizada, sino que, por así decir, nos golpea superficialmente. Esto significa que el sabio estoico no es un ser que ha perdido su sensibilidad natural ante los eventos, solo que no realiza juicios apresurados guiados por la apariencia de las cosas. En cualquier momento, un evento puede suscitar una súbita palidez, un salto del corazón, cierto temblor en los miembros o una leve excitación sexual, todos esos movimientos corporales pueden ser provocados por la sola apariencia, sin asentimiento ni juicio. Pero, en esas situaciones, no hay propiamente pasiones: son meros movimientos corporales. Únicamente cuando la apariencia es interiorizada se produce, en el acto mismo de reconocimiento, el tumulto de la mente en que consiste la emoción (Sorabji, 2000).

Para los estoicos es claro, entonces, que las emociones no son reacciones automáticas, sino que el agente actúa siguiendo su propio juicio (juicio que en la teoría estoica se identifica con la emoción). El punto decisivo sigue siendo el estado cognitivo del agente y el hecho de que tal estado cognitivo se refleje en el carácter, porque, en realidad, según los estoicos, el estado cognitivo de cada uno es su carácter. De los juicios se derivan las cuatro pasiones fundamentales que mencionábamos al inicio de este apartado: a) el juicio de que lo que está actualmente delante de nosotros es bueno, genera placer; b) el juicio de que algo todavía futuro es bueno o valioso produce deseo o apetito; c) el juicio de que lo que está actualmente delante de nosotros es malo, produce tristeza o aflicción; y d) el juicio de que algo todavía futuro es malo produce temor (Boeri \& Salles, 2000; Brun, 1977).

Con estas apreciaciones, podemos reconocer con mayor precisión el ideal estoico de suprimir o extirpar las emociones. Se trata de un tratamiento terapéutico en el que lo central es un esclarecimiento cognitivo que permita al agente cambiar radicalmente su disposición psicológica, es decir, sus creencias. Esto conduciría, no a una completa aniquilación de la esfera afectiva del individuo, pues el sabio estoico puede 
continuar siendo gentil, calmado, afable, generoso o encantador porque entiende lo que sucede a los demás seres humanos en el diario vivir. Se trata, más bien, de un estado en el que el hombre controla sus impulsos excesivos porque están alineados con la razón. Las pasiones son estados característicamente excesivos y la razón viene en ayuda del sabio para hacerle comprender el escaso valor que tienen los bienes externos para la virtud. Según Crisipo, las creencias pueden llegar a ser patológicas (nosemas) cuando se convierten en condiciones estables de la personalidad, algo así como ideas reforzadas cada vez más por el individuo que se consolidan día tras día porque de manera progresiva se llegan a considerar muy deseables cosas que no lo son (Nussbaum, 2003).

Cuando el discípulo ha aprendido mediante la argumentación filosófica que sus creencias acerca de las cosas externas son falsas, empieza su recuperación. Así, en una situación real de peligro, el sabio será afectado, pero no como el que lo es por el miedo, sino como el que puede ser afectado por la precaución. Los libros de Séneca sobre la ira son paradigmáticos en esta visión de la filosofía como medicina del alma. Para este autor estoico, la ira, por ejemplo, es un artefacto social, un producto de lo que se nos enseña a creer y juzgar, por eso, es tan frecuente y causa de mucho descontrol, pues por naturaleza nos imposibilita para detenernos donde queremos (Brennan, 2005).

Si desde niños somos educados en la creencia de que cualquier injuria debe ser castigada o vengada con violencia, poco a poco, nos volveremos seres coléricos incapaces de medir las consecuencias de nuestras acciones. Toda cólera incluye la creencia de que se ha cometido una ofensa deliberada, que esta es en cierto modo importante, y que sería bueno que la venganza cayera sobre el que la ha cometido. Por este camino, la enfermedad del alma se acentúa, por el contrario, los que buscan la sabiduría deben educarse en la indiferencia o apatheia, que consiste en no tener en cuenta el contenido cognitivo de las emociones (Boeri, 2003).

El caso de la guerra y la defensa de la patria es más extremo para el manejo de la ira. Algunos autores antiguos defendían la necesidad de la ira para estimular a los soldados a la guerra, es decir, hacerles ver que el enemigo ha hecho una ofensa a la nación que debe pagar con la muerte. Tal es el caso de la ira de Aquiles, quien, no satisfecho con dar muerte a Héctor, el héroe de Troya, decide arrastrar con violencia su cuerpo por todo el campo hasta destrozar sus miembros. No obstante, el sabio estoico tiene sus reparos, pues considera que se puede ser buen soldado sin recurrir al estímulo de la ira. 
El soldado estoico pensaría que en realidad nada de lo que está sucediendo en una guerra tiene demasiada importancia, que los males y ultrajes acompañan inevitablemente la vida humana, que eso es todo lo que uno puede esperar en la relación con los demás (Nussbaum, 2003). Siendo así, no vale la pena indignarse ni lamentarse demasiado; si decide combatir al enemigo, sea en el campo de batalla o en los tribunales, lo hará, no porque conceda un valor intrínseco a la reparación de algún crimen u ofensa, sino porque ha llegado a la convicción de que el universo exige eso de él, algo así como seguir un destino inexorable, pero sin cólera. Es decir, esas acciones carecen del valor que es necesario o constitutivo de la eudaimonía; sin esos bienes o sin esas acciones la vida de uno sigue siendo completa.

Séneca es partidario de la idea según la cual una persona no colérica puede, sin embargo, interesarse a fondo por la humanidad y sentirse motivada a su favor, sin necesidad de compartir los juicios de la persona colérica. En este sentido, ciertamente el estoico es muy distante del típico vengador romano antiguo o del soldado actual que quiere restaurar con ira las situaciones de injusticia cometidas en campos de concentración o en guerras tribales en África. Si seguimos así, afirma Séneca, con el tiempo nos volvemos menos humanos, y nos vamos encontrando unos a otros de día en día bajo una forma de vida que nos muestra recíprocamente como combatientes en un espectáculo de gladiadores, como monstruos feroces más que como amables humanos (Nussbaum, 2003).

La ira se puede enraizar fuertemente en nuestra mente y, con frecuencia, para la justicia empezamos a tener un endurecimiento contra individuos o grupos, lo cual es el primer paso en el camino que lleva a la brutalidad, a una ruptura en los acuerdos humanos. Manifiesta Nussbaum que "el fiero, desmedido y sanguinario poder de la cólera solo puede ser contrarrestado por el poder de la razón, el único poder lo bastante fuerte como para hacer temblar a aquel" (2003, p. 530). Vista desde este ángulo, la apelación estoica a abstenernos de la ira parece no tanto una manera de desentendernos de las necesidades humanas y de la importancia que pueden tener algunas condiciones externas que rodean la vida humana, sino más bien es una estrategia para consolidar nuestros vínculos profundos con los semejantes, para preservar algo del natural comportamiento abierto y cariñoso hacia los demás.

Con respecto a las ideas que aquí vamos exponiendo, las doctrinas estoicas a veces varían en matices y radicalidad. Séneca mantiene el rigor del pensamiento estoico y 
llega, incluso, a cuestionar desde sus ideas cosmopolitas las creencias populares según las cuales la familia y la ciudad poseen enorme importancia para la vida buena. Hoy en día, podemos identificar esto con el nacionalismo, con el patriotismo mal entendido, con la idea de etnia, de raza o de grupo, asuntos que exacerban los sentimientos negativos hacia otros. Tal como sucedió en la antigua Yugoslavia, en que serbios, croatas y bosnios vivían en un mismo edificio pacíficamente, luego de un momento a otro empezaron a verse con recelo, con ira, recordando incluso las ofensas recibidas en siglos pasados. La creencia de que el otro era un traidor trajo la cólera, la ira se apoderó de todos, las etnias emergieron de los más diversos rincones reclamando la tierra que les pertenecía y proclamando la necesidad de un castigo para los que no merecían estar allí. La guerra y los crímenes habían empezado.

En contraposición con estas ideas nacionalistas actuales, Séneca sostiene una actitud más cosmopolita que ayuda al cultivo de la humanidad, permitiéndonos seguir profundamente interesados por el bien y el mal de los demás, sin reacciones que pudieran romper los vínculos de ese interés. El estoico cultivará lo que a veces parecerá una forma alarmante de distanciamiento, pero para el sabio es la manera más auténtica de conservar una sincera simpatía por todos los seres humanos. La ataraxia o imperturbabilidad de las emociones es, pues, la vía para la felicidad a la que todos aspiramos en esta corta y efímera existencia; también es la verdadera y única paz del alma.

\section{Conclusiones}

Terminada la exposición del estoicismo, podemos hacer una breve recapitulación de lo expuesto sobre las emociones en la filosofía antigua. Los filósofos griegos tenían como preocupación fundamental en sus reflexiones éticas establecer unos parámetros de cómo debía ser una vida que mereciera ser valorada como propia del ser humano o floreciente dentro de un contexto social. En este propósito, la ética establecía particulares concepciones sobre la naturaleza humana y sobre los fines que esta naturaleza debía alcanzar para que el ser humano llegara a su verdadera plenitud en este mundo. Esta visión teleológica establecía ideales de vida buena que se convertían en principios rectores de la acción y en demandas de comportamiento a través de las cuales se podía calificar la conducta de los ciudadanos de virtuosa o digna de condena por los vicios que la orientan. En este sentido, la reflexión filosófica era propuesta como aquellos ideales que garantizaban una buena formación o excelencia de los ciudadanos y sentaban las bases para lograr un tipo de bienestar para toda la comunidad política. 
De acuerdo con lo anterior, el contexto de todo lo expuesto acerca de la concepción de las emociones en la Antigüedad debe entenderse como un ejercicio filosófico por establecer ciertas formas de vida virtuosa y por promover en los ciudadanos diversos ideales de comportamiento que solo podían ser alcanzados por el refinamiento de ciertas pasiones, en unos casos, o el dominio o extirpación de las emociones según otras posturas más extremas. Estas discusiones y divergencias entre los distintos autores alrededor de la felicidad, las virtudes, los ideales de perfección, la vida buena y las conductas que debían ser condenadas fueron modelando las distintas visiones que en adelante se desarrollaron en torno a la naturaleza de las pasiones o emociones. Destaca en estas discusiones el fuerte contenido valorativo bajo el cual se comprendieron estos fenómenos humanos, de tal forma que se desprendieron posturas dicotómicas entre razón y emoción en las que se asociaban a estas últimas con una naturaleza baja, un espíritu de esclavo, unos juicios errados, actitudes que demostraban falta de prudencia y unos deseos desordenados que alejaban al hombre de su auténtica felicidad.

Salvo las ideas aristotélicas que no reducían la pasión a una faceta negativa, todos los autores expuestos se referían a las emociones para hacer énfasis en conductas que consideraban debían ser condenadas. La pasión era asociada a la expresión de fuerzas animales, o a actitudes de esclavo en la obra de Platón. En los epicúreos, la pasión era la expresión de unos intereses que condenaban por descuidar las formas de desprendimiento y de gusto estético y espiritual que tanto valoraban. Para los estoicos, la pasión era la consecuencia de pensamientos irracionales cimentados en falsas creencias y en valoraciones inestables que se daban por un confuso y desproporcionado asentimiento a la apariencia de los hechos.

Así, desde sus primeros días, el concepto de pasión asumió un sentido negativo y la consecuencia de un razonar equivocado. Si bien los autores estoicos reconocieron un componente cognitivo en las pasiones, entendieron estas bajo el supuesto de que eran manifestación de un juicio o proceso cognitivo errado, asunto que dio paso a la comprensión de las pasiones como el componente de la vida humana opuesto a la recta razón. Esta comprensión negativa inicial conduciría al surgimiento de diversas posturas filosóficas que defenderían una radical separación entre razón y emoción, y a una más evidente condena de la pasión por ser el espacio en que el juicio brilla por su ausencia. El cristianismo medieval será heredero de estas discusiones y llevará la dicotomía razón-emoción a otro nivel en el que el cuerpo y las pasiones se vincularan al pecado y al alejamiento de Dios, y el dominio de estas se verá como la conducta 
del hombre virtuoso que anhela la salvación. Estos aspectos constituirán la segunda parte de esta breve historia de las emociones que en un próximo número esperamos dar a conocer.

\section{Referencias}

Aristóteles. (1985). Ética nicomaquea. Ética eudemia (J. Palli Bonet, trad.). Madrid, España: Gredos.

Aristóteles. (1994). Retórica (Q. Racionero, trad.). Madrid, España: Gredos.

Aristóteles. (1988). Fedro. En Diálogos. Madrid, España: Gredos.

Aristóteles. (2010). Acerca del alma (De anima) (M. D. Boeri, trad.). Buenos Aires, Argentina: Colihue clásica.

Bben-Ze'ev, A. (2004). Emotions are not mere judgments. Philosophy and Phenomenological Research, 68(2), 450-457.

Bergua, J. (1936). Los estoicos. Epicteto: Máximas; Marco Aurelio: Pensamientos; Boecio: De la consolación por la filosofía. Madrid, España: Librería Bergua.

Boeri, M. D. (2003). Los estoicos antiguos: sobre la virtud y la felicidad. Santiago de Chile, Chile: Editorial Universitaria.

Boeri, M. D. y Salles, R. (2014). Los filósofos estoicos: ontología, lógica, física, ética. Sankt Augustin, Alemania: Academia Verlag.

Brennan, T. (2005). The stoic life: Emotions, duties, and fate. Oxford, RU: Oxford University Press.

Brun, J. (1977). El estoicismo. Buenos Aires, Argentina: Eudeba.

Clore, G. (1994). Why Emotions require cognition. En R. J. Davidson \& P. Ekman (Eds.), The nature of emotion: Fundamental questions (pp. 181-191). Nueva York, EE. UU.: Oxford University Press.

Cooper, J. M. (1999). Reason and emotion: Essays on ancient moral psychology and ethical theory. Princeton, EE. UU.: Princeton University Press.

Deigh, J. (1994). Cognitivism in the theory of emotions. Ethics, 104(4), 824-854. 
Dixon, T. (2006). From passions to emotions: The creation of a secular psychological category. Nueva York, EE. UU.: Cambridge University Press.

Dow, J. (2015). Passions and Persuasion in Aristotle's Rhetoric. Oxford, UK: Oxford University Press.

Fitzgerald, J. (2008). Passions and moral progress in Greco-Roman thought. New York, EE. UU.: Routledge.

Graver, M. R. (2007). Stoicism and emotion. Chicago, EE. UU.: The University of Chicago Press.

Knuuttila, S. (2004). Emotions in ancient and medieval philosophy. Oxford, RU: Clarendon Press.

Leclercq, J. (1956). Las grandes líneas de la filosofía moral. Madrid, España: Gredos.

Long, A. (1975). Filosofía helenística (J. Urries, trad.). Madrid, España: Revista de Occidente.

Long, A. A. \& Sedley, D. N. (1989). The Hellenistic Philosophers. Volume 2: Translations of the Principal Sources, with Philosophical Commentary. Nueva York, EE. UU.: Cambridge University Press.

Nussbaum, M. (1987). The stoics and the extirpation of the passions. Apeiron, 20(2), 129-178.

Nussbaum, M. (1995). La fragilidad del bien: fortuna y ética en la tragedia y la filosofía griega. Madrid, España: Visor.

Nussbaum, M. (2003). La terapia del deseo: teoría y práctica en la época helenística. Barcelona, España: Paidós.

Nussbaum, M. (2008). Paisajes del pensamiento: la inteligencia de las emociones (A. Maira, trad.). Barcelona, España: Paidós.

Oatley, K. (2004). Emotions: A brief history. Malden, EE. UU.: Blackwell Publishing. Pasquali, A. (1970). La moral de Epicuro. Caracas, Venezuela: Monte Ávila.

Plamper, J. (2015). The history of emotions: An introduction. Oxford, RU: Oxford University Press. 
Rowe, C. (2007). La ética de la Grecia antigua. En P. Singer (ed.), Compendio de ética (pp. 183-195). Madrid, España: Alianza.

Solomon, R. (2003). Not passions slave: Emotions and choice. Oxford, UK: Oxford University Press.

Sorabji, R. (2000). Emotion and peace of mind: From stoic agitation to Christian temptation. Oxford, RU: Oxford University Press.

Trueba Atienza, C. (2009). La teoría aristotélica de las emociones. Signos Filosóficos, 22(1), 147-170.

Villamil Pineda, M. Á. (2011). Emociones y ética: aportes al desarrollo de una ética integral. Franciscanum, 53(156), 171-209. 